\title{
A STRONG, STERILIZABLE DIALYZING MEMBRANE.
}

By HIBBERT WrxsLOW HIIL.

Received June 23,1905 .

THE USE of dialyzing membranes in chemistry and physics has been long established. In the effort to apply dialysis to bacteriological problems, difficulties were found, principally due to the necessity for sterilization of all materials used, in order to prevent complications arising from the action of bacteria other than those under investigation. One material after another, physically adapted for dialysis, was rejected because it could not be sterilized satisfactorily. Collodion, dissolved in ether and alcohol, and by dexterous manipulation converted into test-tube-like sacs, received much attention from bacteriologists, since sterilization of such sacs is possible, and dialysis rapid. The technique, however, is very exacting; everything must be just right to secure results at all reliable; the collodion tissue is very fragile; and little satisfactory work is known to the writer as having been successfully done in dialyzing bacterial products by this method.

The method here to be described is extremely simple. While designed primarily for bacteriological purposes, it may be of interest to chemists and physicists also.

The resulting membrane is exceedingly strong; it can be handled, dry or wet, without injury; it may be repeatedly sterilized in boiling water, free steam or steam under pressure, and dialyzes well. It dialyzes less readily than does fresh collodion, which is, however, rather an advantage, for fresh collodion membranes, if not allowed to dry, dialyze so quickly as to suggest leakage, while if once dried, collodion membranes, in the writer's experience at least, become irremediably waterproof. The membrane here described can be set aside to dry, and, except that in this condition it is somewhat brittle, and by exceedingly rough handling may be injured, no evil result necessarily follows, the membrane becoming soft, pliable and permeable again immediately on immersion in water.

The chief advantages of this method are the multiplicity of sizes and shapes in which the membranes may be made, the strength of the membranes, their sterilizability and the simplicity of the technique, which, among other things, permits the testing of the integrity of the membranes at a stage where, if flaws are found, they can be eliminated before going further. 
While not aware of anything similar already published, the writer has not been able to go into the literature of the subject sufficiently to satisfy himself that the method is strictly new.

Technique.-I. Make, from close-meshed, rigidly woven silk, square, circular, cylindrical, conical, bag-shaped or otherwise-shaped "frames" to act as the bases of the membrane desired. White taffeta silk, costing about one dollar a yard, is entirely satisfactory; also the silk used in the Edison mimeograph process, for taking the wax impression. The seams, if cylindrical, conical or other shapes of membrane in more than one plane are desired, should be flat and sewed double or treble, very firmly (best with a sewing-machine), the object being to leave no part of the seam less close or rigid than the mesh of the silk itself. Square or circular frames, and the mouths of bag-shaped frames, may be hemmed, making them practically untearable.

2. Dip this "frame" into a hot, filtered, 20 to 30 per cent. aqueous solution of gelatin standing on a water-bath at or near $100^{\circ} \mathrm{C}$. Leave it in the hot gelatin long enough to thoroughly saturate the interstices of the silk strands as well as to fill the meshes, i. e., about ten to fifteen minutes.

3. Raise the "frame," lifting it by safety-pins attached to its edges and allow it to drain freely. Safety-pins are used, because at this stage and later the membrane is extremely slippery. With the high percentages of gelatin prescribed, it is unlikely to drain too much (i.e., until too thin a film remains) at ordinary room temperatures, but if any doubt is felt on this point, it is sufficient to reimmerse and quickly withdraw one or more times, until the operator is satisfied with the thickness and homogeneity of the film.

4. When the gelatin nolonger drips from the frame plunge the now "gelatinized frame" into ice-cold water and leave it there to "set" for five or ten minutes. It would seem sufficient that the temperature of the water should be merely just below the meltingpoint of the gelatin solution used, but it is safest and most satisfactory to have the temperature as nearly as possible at $o^{\circ} \mathrm{C}$. The writer keeps blocks of ice floating in the water to insure this.

5. Raise the "gelatinized frame" from the water and test it for leaks by filling it with ice-cold water. Water warm enough to melt the gelatin, or even to soften it, may at once create flaws, in the very process of testing itself. 
6. If no flaws are discovered, plunge the "gelatinized frame" into ice-cold formalin ( 40 per cent.) and transfer the formalin to an ice-chest where it should remain until, by the action of the formalin, the gelatin is rendered completely insoluble in boiling water. Two weeks' time has proven entirely satisfactory for this purpose. Perhaps less time may be found sufficient.

7. Wash the now completed membrane in running water, or boil it, or steam it in free steam or in steam under pressure, to get rid of the free formalin adherent to the gelatin.

If at step 5, flaws are found (there should be none, however, if ordinary care be taken), it is best to return the "frame" to the hot gelatin solution and leave it there for ten or fifteen minutes more, at or near $100^{\circ} \mathrm{C}$., to remelt the gelatin already cooled upon it, and reimpregnate the whole silk tissue. Patching flaws found in cold gelatin films with hot gelatin is not likely to yield satisfactory results.

The essentials of success are, the writer believes, first, fine, rigid meshes in the "frame;" second, close, firm, rigid seams, if the "frame" is sewed at any point; third, thorough impregnation with hot gelatin; fourth, ice-cold temperatures for the water used in setting and testing and for the formalin used in hardening; fifth, sufficient time for the formalin to act thoroughly on the gelatin. The writer has used Gold Label Brand gelatin, Comte Fils, Magdebourg, but any good sheet gelatin would probably be satisfactory.

BOARD OF HEALTH, BACTERIOLOGICAL LABORATORY, BOSTON.

[CONTRIBUTIONS FROM THE HAVEMEYER LABORATORIES, COLUMBIA UNIVERSITY, No. 108.]

\section{COMPARATIVE EXPERIMENTS UPON CHEMICAL PRE- SERVATIVES IN MILK.}

By H. C. Shermax, A. W. HahN, AND A. J. Mettler.

Received July 16, 1905.

IN CONNECTION with other studies concerning the composition and analysis of milk, experiments upon the detection and determination, efficiency, and mode of action of chemical preservatives have been undertaken in this laboratory. The destruction of lactose and the development of acidity under the influence of sodium fluoride, sodium salicylate, and a mixture of boric acid and borax, together with notes on the determination of these com- 